\title{
Laboreal
}

Volume $3 \mathrm{~N}^{\circ} 1$ | 2007

Varia

\section{Envelhecimento, trabalho e cognição : do laboratório para o terreno na construção de uma alternativa metodológica}

Envejecimiento, trabajo y cognición : del laboratorio hacia el terreno en la construcción de una alternativa metodológica

Vieillissement, travail et cognition : du laboratoire au terrain dans la construction d'une alternative méthodologique Ageing, work and cognition : from lab to the field in the construction of a methodological alternative

\section{Sara Ramos}

\section{OpenEdition}

\section{Journals}

\section{Edição electrónica}

URL: http://journals.openedition.org/laboreal/12954

DOI: $10.4000 /$ laboreal. 12954

ISSN: 1646-5237

\section{Editora}

Universidade do Porto

\section{Refêrencia eletrónica}

Sara Ramos, «Envelhecimento, trabalho e cognição : do laboratório para o terreno na construção de uma alternativa metodológica », Laboreal [Online], Volume $3 N^{0} 1 \mid$ 2007, posto online no dia 01 julho 2007, consultado o 24 setembro 2020. URL : http://journals.openedition.org/laboreal/12954 ; DOI https://doi.org/10.4000/laboreal.12954

Este documento foi criado de forma automática no dia 24 setembro 2020.

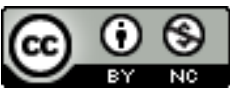

Laboreal está licenciado com uma Licença Creative Commons - Atribuição-NãoComercial 4.0 Internacional. 


\section{Envelhecimento, trabalho e cognição : do laboratório para o terreno na construção de uma alternativa metodológica}

Envejecimiento, trabajo y cognición : del laboratorio hacia el terreno en la construcción de una alternativa metodológica

Vieillissement, travail et cognition : du laboratoire au terrain dans la construction d'une alternative méthodologique

Ageing, work and cognition : from lab to the field in the construction of a methodological alternative

\section{Sara Ramos}

\section{REFERÊNCIA}

Ramos, S. (2006). Envelhecimento, trabalho e cognição : do laboratório para o terreno na construção de uma alternativa metodológica. Tese de Doutoramento. Faculdade de Psicologia e de Ciências da Educação da Universidade do Porto, Porto.

\section{NOTA DO EDITOR}

Manuscrito recebido em : Fevereiro/2007

Aceite após peritagem em : Julho/2007 


\section{Tradições teóricas acerca do estudo do envelhecimento}

1 Esta tese apresenta uma interpretação das tradições teóricas que têm caracterizado a problemática do envelhecimento, tentando estabelecer uma possível analogia entre alguns momentos históricos e o predomínio de certas correntes teóricas.

2 De forma muito sucinta, podemos considerar quatro momentos fundamentais na história do estudo do envelhecimento cognitivo. Um momento inicial em que se privilegiou o estudo de capacidades básicas (como a memória, a atenção e a percepção) e a que correspondeu a emergência das chamadas ciências cognitivas (Teiger, 1995; Varela, 1986). Com o desenvolvimento das abordagens situacionais, o estudo da cognição começa a ter em conta não apenas as capacidades do indivíduo mas também a relação destas com a prática e com o contexto. Ao considerar os factores situacionais, $o$ trabalho surge como possível contexto de desenvolvimento (ou não) da dimensão cognitiva, sendo aqui que a problemática se assume como objecto de uma psicologia do trabalho de tradição ergonómica - orientada para a transformação das situações de trabalho e ancorada na actividade real do trabalhador (Leplat \& Cuny, 1983).

3 No entanto, é no seio da própria disciplina que procurámos uma abertura teórica, num movimento que sai do trabalho para o trabalhador, para a forma como este constrói a sua actividade e para a relação que estabelece com o seu trabalho, tentando integrar na démarche outros contextos de vida, traduzindo uma concepção renovada da própria disciplina.

\section{Consequências metodológicas}

4 Aos diferentes momentos históricos já referidos podemos fazer corresponder uma evolução relativa às diferentes tradições metodológicas que se foram assumindo neste domínio. À tradição psicométrica associada ao estudo das capacidades seguiu-se uma abordagem menos experimental que saiu do laboratório para o terreno, enfatizando a importância do contexto. Quanto ao estudo da relação entre cognição e actividade de trabalho, a análise ergonómica do trabalho assume um papel central na démarche defendida por esta psicologia do trabalho.

5 Todavia, no que respeita à consideração de outros contextos de vida, têm sido conduzidos estudos que dão conta da interdependência entre o contexto de trabalho e a dimensão pessoal (Curie, 2000 ; Curie \& Hajjar, 1987) mas é crescente a referência à necessidade de considerar esta interdependência no domínio concreto do estudo do envelhecimento, bem como os elementos dos itinerários profissional e pessoal dos trabalhadores.

6 A participação no Estudo SIT - Saúde, Idade e Trabalho (Duarte, Ramos, Cunha, \& Lacomblez, 2002) constituiu o ponto de partida que nos conduziu a um processo de construção metodológica. Trata-se de um estudo desenvolvido no Sector Têxtil, decorrido em 2001 e que teve por base um instrumento - o Inquérito SIT. Este instrumento, concebido na sequência de dois outros, ESTEV - Enquête Santé, Travail Et Vieillissement (Derrienic, Touranchet, \& Volkoff, 1996) e VISAT - VIeillissement, SAnté et Travail (Marquié et al., 2002), articula os princípios de uma psicologia do trabalho de tradição ergonómica (nomeadamente, a caracterização do posto de trabalho, das 
condições de trabalho e dos riscos para a saúde) com medidas de carácter psicométrico (testes de memória, atenção, etc.).

\section{A construção da metodologia}

7 Num primeiro momento, procedemos a uma reflexão sobre os dados do Estudo SIT. Este preliminar quantitativo veio evidenciar a existência de múltiplas influências sobre o desempenho cognitivo medido pelos testes do Inquérito SIT. Ou seja, a idade e a escolaridade, mas também os elementos do contexto de trabalho (determinadas características do trabalho, exposição a certos factores de risco), elementos do contexto de realização dos testes (a actividade relativa ao dia anterior aos testes) e elementos da vida fora do trabalho (história de saúde, escolha da profissão, actividades culturais). Estas primeiras constatações contribuíram para a compreensão, no concreto, das recentes referências que vão no sentido de alargar a abordagem tradicional da psicologia do trabalho de tradição ergonómica às relações entre os diferentes contextos de vida, em considerar não só o itinerário profissional mas também a história pessoal e social dos indivíduos.

8 Foi neste sentido que procurámos desenvolver, no terreno, uma démarche complementar, que se situe para além quer do estudo das capacidades individuais, quer da influência isolada da situação de trabalho, a qual designámos de Método da reconstituição biográfica centrada no trabalho e que envolveu a articulação de dois instrumentos - a Entrevista de reconstituição biográfica e o Bio-gráfico.

\subsection{Bio-gráfico}

9 O bio-gráfico consiste num suporte gráfico para as entrevistas, assumindo o papel de guião. É composto por cinco campos temáticos organizados sobre uma linha cronológica central : percurso profissional, história de saúde, percurso escolar, história familiar e meio social e geográfico. Este instrumento esteve sempre presente nas entrevistas, sendo progressivamente construído após a transcrição de cada entrevista, bem como restituído e validado com o trabalhador na entrevista seguinte.

\subsection{Entrevistas de reconstituição biográfica}

10 A preparação das entrevistas implicou a selecção de uma amostra restrita de trabalhadores entre os participantes do Estudo SIT que obtiveram resultados contrastados nos testes cognitivos, procurando respeitar critérios de diversidade de idade, sexo, tipo de actividade profissional e de empresa.

11 As entrevistas de reconstituição biográfica seguem as linhas globais das entrevistas semi-estruturadas mas com um carácter biográfico, tendo-se realizado diferentes entrevistas com cada participante. Após o estabelecimento do contrato de colaboração, o trabalhador inicia a construção da sua narrativa a partir das suas primeiras recordações da infância, avançando progressivamente na linha da idade. Esta construção prossegue nas entrevistas seguintes, a partir da restituição da entrevista anterior, a qual permite que ambos (entrevistado e entrevistador) se (re)situem na linha cronológica. 


\section{Resultados do método desenvolvido}

Todas as entrevistas foram objecto de registo e transcrição integrais, tendo-se efectuado uma análise de conteúdo. Esta análise implicou a construção de um cenário de categorias emergentes do próprio discurso, onde foram retomados os cinco campos temáticos do bio-gráfico.

13 A análise de conteúdo revelou algumas pistas, nomeadamente, no que respeita à importância atribuída pelos participantes aos diferentes contextos de vida; às características específicas dos itinerários femininos e masculinos; ao sentido que o trabalho e a vida profissional representam para os indivíduos e a evolução construída num quadro de permanente gestão de prioridades. Estas pistas indiciam que a distinção dos sujeitos com base nos resultados obtidos nos testes cognitivos é questionável, sobretudo quando constatamos a presença de reveladores cognitivos no discurso dos participantes que obtiveram uma performance mais baixa nos testes cognitivos do SIT.

Neste sentido, duas ideias saem reforçadas : que certas capacidades cognitivas parecem não ser consideradas pelos testes embora se manifestem na prática quotidiana ; e que a influência dos factores situacionais releva não só do contexto de trabalho mas também de outros contextos de vida, o que vem reforçar a importância de considerar estes "outros contextos" ao nível metodológico.

15 Apesar da especificidade e dos limites da nossa proposta, esta pode constituir um complemento relativamente às abordagens centradas no trabalho e que têm dominado o estudo do envelhecimento cognitivo no domínio da psicologia do trabalho. Por outro lado, o confronto entre os dados provenientes do SIT e os dados resultantes do nosso método revelaram alguns pontos de incoerência que podem contribuir quer para a reflexão e transformação do instrumento SIT, quer para a concepção de outro tipo de instrumentos que valorizem o reconhecimento das experiências e das penosidades vividas ao longo do itinerário profissional.

Retomando o enquadramento inicial, esperamos que este trabalho reforce o interesse de uma concepção renovada da psicologia do trabalho, que sai do contexto de trabalho para colocar o trabalhador no centro do processo de investigação (Clot \& Leplat, 2005 ; Oddone, Re, \& Briante, 1981), reconhecendo a sua história, a sua experiência, a sua vivência subjectiva e o seu papel enquanto agente de mudança, quer da realidade quer de si mesmo.

\section{BIBLIOGRAFIA}

Clot, Y., \& Leplat, J. (2005). La méthode clinique en ergonomie et en psychologie du travail. Le Travail Humain, 68, 4, 289-316.

Curie, J. (2000). Travail, Personnalisation, Changements sociaux. Archives pour les histoires de la psychologie du travail. Toulouse : Octarès Éditions

Laboreal, Volume $3 \mathrm{~N}^{\circ} 1$ | 2007 
Curie, J., \& Hajjar, V. (1987). Vie de travail, vie hors travail : la vie en temps partagé. In C. LévyLeboyer e J-C. Sperandio (Eds.), Traité de Psychologie du Travail (pp. 37-55). Paris : PUF.

Derrienic, F., Touranchet, A., \& Volkoff, S. (1996). Âge, travail, santé. Études sur les salariés agés de 37 à 52 ans. Enquête ESTEV 1990. Paris : INSERM.

Duarte, C., Ramos, S., Cunha, L., \& Lacomblez, M. (2002). Da organização do trabalho à saúde ocupacional : análise das condições da actividade profissional na indústria têxtil e do vestuário a especificidade do trabalho feminino. Porto : IDICT.

Leplat, J., \& Cuny, X. (1983). Introdução à psicologia do trabalho. Lisboa : Fundação Calouste Gulbenkian.

Marquié, J.-C., et al. (2002). Aging, health, work : overview and methodology of the VISAT prospective study. Le Travail Humain, 65, 3, 243260.

Oddone, I., Re, A., \& Briante, G. (1981). Redécouvrir l'expérience ouvrière. Vers une autre psychologie du travail ? Paris : Éditions Sociales.

Teiger, C. (1995). Penser les relations âge/travail au cours du temps. In J-C. Marquié, D. Paumès e S. Volkoff (Eds.), Le travail au fil de l'âge (pp. 15-72). Toulouse : Octarès Éditions

Varela, F. (1986). Connaître les sciences cognitives, Tendances et Perspectives. Paris : Éditions du Seuil.

\section{AUTOR}

\section{SARA RAMOS}

Universidade do Porto - Faculdade de Psicologia e de Ciências da Educação Rua Dr. Manuel Pereira da Silva, 4200-392 Porto

scramos@gmail.com 